\title{
Frozen Shoulder: Ambulatory Treatment with Hydraulic Distension
}

\author{
Ricardo Monreal $^{1 *}$, Yblin Severiche ${ }^{2}$, Giovanni Osinaga ${ }^{3}$ and Eilen Monreal ${ }^{4}$ \\ ${ }^{1}$ Centro Médico MEDEX, República de Panamá 30652 do piso, Peru \\ ${ }^{2}$ Caja Petrolera de Salud, Santa Cruz, Bolivia \\ ${ }^{3}$ Hospital Obrero No. 3, Caja Nacional de Salud, Santa Cruz, Bolivia \\ ${ }^{4}$ Medical Student (MS), School of Medicine, Ricardo Palma University, Peru
}

Submission: August 24, 2017; Published: August 29, 2017

*Corresponding author: Ricardo Monreal, Centro Médico MEDEX, República de Panamá 3065 2do piso, San Isidro, and Clínicas Maison de Santé, Ave. Chorrillos 171, Chorrillos, Lima, Peru, Email: rmonreal59@yahoo.es

Abstract

Purpose: Frozen shoulder syndrome has been an enigma to orthopaedic surgeons. The current treatment ranges from observation of this condition described as self-limiting, to manipulation under anaesthesia, to surgical release and in the last years arthroscopy treatment has been recommended. During the past eight years, we have observed that local infiltration of anaesthesia and hydraulic distension of glenohumeral joint have been a successful alternative for the management of this condition. Although similar techniques have been mentioned in the literature, they have been given little attention.

Materials and Methods: Twelve patients were seen and diagnosed as having frozen shoulder syndrome. All patients were treated ambulatory with hydraulic distension and followed between six months to one year. Median patient age was 44.7 years with a range from 26 to 70 years of age. All patients were treated ambulatory. Four of twelve patients were women. The patients were examined immediately prior to and after treatment to document Range of Motion (ROM).

Results: All patients noted immediate resolution of previous pain. Return to function was $77.3 \%$ for abduction and $80.1 \%$ for IR/ER immediately after the first treatment but at the two-week examination, some loss of motion was noted $\left(10^{\circ}-20^{\circ}\right)$. All patients had continued full function and complete resolution of the symptoms at the four-week follow-up examination. In all cases, shoulder function remained normal at follow-up examination six months to one year later.

Conclusion: Ambulatory treatment of frozen shoulder with hydraulic distension and local anaesthesia and a coordinate effort on the part of the physician, the patient, and the physical therapist is safe, reliable and highly effective.

Level of Evidence: IV Case series

Keywords: Frozen shoulder; Hydraulic distension; Arthroscopy; Adhesive capsulitis; Tenosynovitis; Stiff shoulder syndrome

\section{Introduction}

Frozen shoulder syndrome has been an enigma to orthopaedic surgeons. Codman's description in 1934 [1] attests this enigma: "A class of cases which are difficult to define, difficult to treat and difficult to explain from the point of view of pathology". The current treatment ranges from observation of this condition described as self-limiting, to manipulation under anaesthesia, to surgical release and in the last years arthroscopy treatment has been recommended. During the past eight years, we have observed that local infiltration of anaesthesia and hydraulic distension of glenohumeral joint have been a successful alternative for the management of this condition. Although similar techniques have been mentioned in the literature, they have been given little attention.

\section{Materials and Methods}

Twelve patients were seen and diagnosed as having frozen shoulder syndrome. All patients were followed between six months to one year. Median patient age was 44.7 years with a range from 26 to 70 years of age. All patients were treated ambulatory. Four of twelve patients were women. The patients were examined immediately prior to and after treatment to document Range of Motion (ROM). The range of the baseline abduction averaged $29.6^{\circ}$ pre-treatment and $69.6^{\circ}$ post- 
treatment and the range of the baseline internal-external (IR/ ER) rotation averaged $22.5^{\circ}$ pre-treatment and $144.2^{\circ}$ posttreatment.

Time since onset ranged between three months and nine months (average, 5.3 months). All patients previously had been treated either by physical therapy, nonsteroidal antinflamatory indications, cortisone injections, or oral pain medications. Associated orthopaedic conditions varied: Subacromial tenosynovitis (7 patients), calcific tendonitis (1 patient), rotator cuff tear (1 patient), osteoarthritis of acromioclavicular joint (1 case), elbow fracture (1 patient), and tenosynovitis of the long head of the biceps (3 patients) (Figure 1).

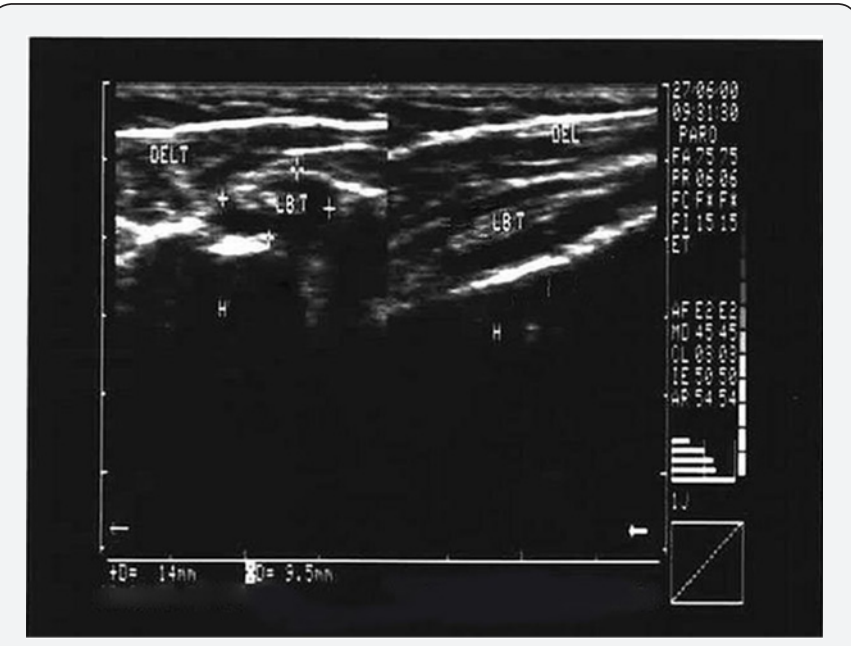

Figure 1: Case 3. Tenosynovitis of the long head of the biceps: Ultrasonography image of the shoulder shows thickening of the long head of the biceps tendon (LBT). H: humeral head, DELT: deltoid.

\section{Technique}

In the supine position, bony landmarks were marked on the skin with indelible ink. These included the coracoid process, the acromion, the distal clavicle, and the humeral head. The arm was held in as much external rotation as possible to facilitate needle placement into the anterior aspect of the joint. The skin was prepared with a povidone-iodine solution. Three millilitres of $1 \%$ lidocaine was injected into the skin and soft tissues overlaying the joint capsule with a 25 -gauge $3.81 \mathrm{~cm}$ needle. Thereafter, 3 $\mathrm{ml}$ de $1 \%$ lidocaine was injected intraarticularly, followed by 1 $\mathrm{ml}$ of betamethasone sodium phosphate mixed with $2 \mathrm{ml}$ of $1 \%$ lidocaine. Distension of the capsule was performed using four $10-\mathrm{ml}$ syringes of refrigerated sterile saline solution through a 22-gauge $3.81 \mathrm{~cm}$ needle. The maximum volume depends on the distensibility of joint capsule. The patient then had active, assisted exercises under supervision of a physician and physical therapist.

The patients continued with regular home physical therapy exercises for a total of four weeks after treatment. This consisted of pendulum exercises, abduction, internal and external rotation, resisted flexion and extension exercises four times daily. At the two-week follow-up examination, patients were examined for ROM. Depending on the percentage of ROM; a second treatment with hydraulic distension was performed at this time. At the four-week follow-up examination, ROM was again documented.

\section{Results}

All patients noted immediate resolution of previous pain. Return to function was $77.3 \%$ for abduction and $80.1 \%$ for IR/ ER immediately after the first treatment but at the two-week examination, some loss of motion was noted $\left(10^{\circ}-20^{\circ}\right)$. All patients had continued full function and complete resolution of the symptoms at the four-week follow-up examination. In all cases, shoulder function remained normal at follow-up examination six months to one year later (Figure 2).

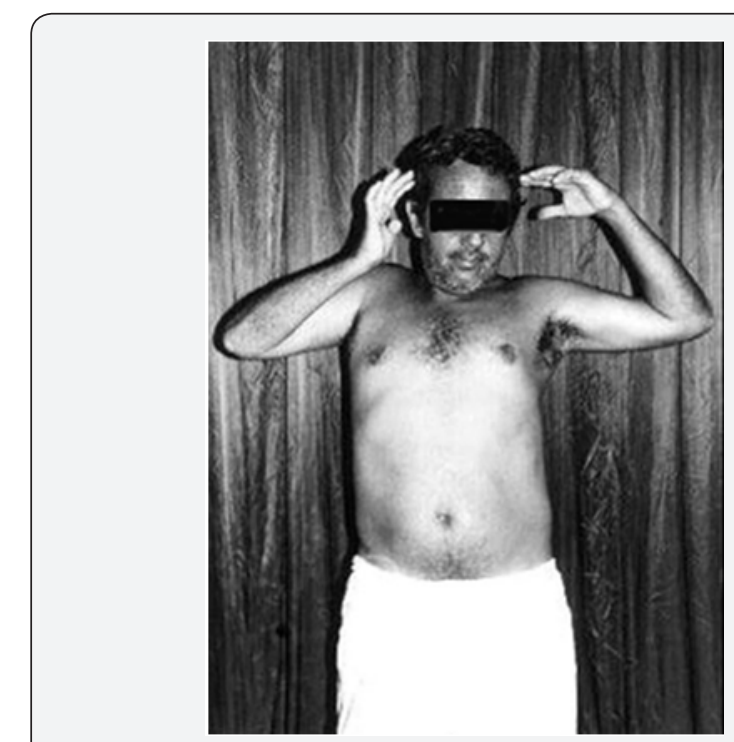

Figure 2: The patient can abduct actively the right shoulder after hydraulic distension with local anaesthesia.

\section{Discussion}

"Frozen shoulder" is a general term denoting all causes of motion loss in the shoulder. The condition is one in which there is both active and passive limitation of motion due to soft-tissue contracture that results in a mechanical block. This soft-tissue contracture can occur in combination with other conditions, such as rotator cuff tear and degenerative arthritis. In the latter, joint incongruity may also limit motion. The painful, stiff shoulder syndrome ("Frozen shoulder") is characterized by a well-known cycle of events: increasingly severe pain in the shoulder, often radiating down the arm as far as the insertion of the deltoid, occurs most frequently in the fourth, fifth, and sixth decades, sometimes being precipitated by a comparatively minor injury; the pain persists and glenohumeral movement decrease; later pain becomes less severe but stiffness persists; gradually the pain resolves and the range of motion is slowly regained.

When discussing the idiopathic form of motion loss in the shoulder, the term "primary adhesive capsulitis" is preferable to 
"frozen shoulder," as it more precisely describes the pathologic changes in the joint capsule. The pathogenesis of this idiopathic condition remains a subject of debate. Possible causes include immunologic, inflammatory, biochemical, and endocrine alterations [2-5]. Systemic disorders, such as diabetes mellitus, cardiovascular disease, and neurologic conditions, can also be contributing causes. Regardless of the biologic cause, adhesive capsulitis is characterized by thickening and contracture of the joint capsule, [5-9] which results in decreased intra-articular volume and capsular compliance so that glenohumeral motion is limited in all planes. The natural history of primary adhesive capsulitis is well described and has been termed benign because it tends to resolve over the course of 1 to 3 years $[4,5,9]$. Despite this favourable natural history, some patients develop a painful limitation of motion while they wait for resolution of this condition. Most patients will have some residual loss of motion even after many years, although the literature suggests that most do not have serious functional limitations or pain [9].

Secondary, or acquired, shoulder stiffness develops when there is a known intrinsic, extrinsic, or systemic cause [9-12]. Examples include postsurgical and posttraumatic stiffness, which can occur with or without an associated fracture. Both types of shoulder stiffness usually occur in association with prolonged immobilization. While the management of primary adhesive capsulitis is usually conservative with physical therapy, most surgeons believe that acquired stiffness of the shoulder after surgical procedures for instability merits more aggressive treatment because of the potential unfavourable consequences [2,9-15].

Initially treatment is rest and relief of pain, with physiotherapy in the form of active exercises being recommended as the severity of the pain decreases. The role of manipulation has been controversial since it was described by Duplay in 1872 [16]. In the early phase, though theorically it may cause further damage in the form of scarring, there are no serious complications. In the later stages, when there is persistent pain and stiffness, manipulation under anaesthesia is often associated with severe pain and mechanical complications such as fracture and subluxation of the joint. Some authors [1719] have recommended hydrostatic pressure to rupture the capsule. De Palma [20] has suggested that, before manipulation, one should distend the joint with saline solution under pressure until free flow is established. Reeves [21] reported favourable results in patients treated with serial distension.

The frozen shoulder results from localized synovitis involving the nameless triangle between the long head of the biceps and subscapularis tendons and, humeral head, and glenoid [22]. In the normal no inflamed situation, insufflation of the joint causes the tissue to evaginated, forming the coracoid and axillary recesses, which are lost in the frozen shoulder. Hydraulic distension allows elevation of this delicated inflamed tissue off of the adjacent structures and establishes a normal mechanical range of motion of the joint.

\section{Conclusion}

In conclusion, ambulatory treatment of frozen shoulder with hydraulic distension and local anaesthesia and a coordinate effort on the part of the physician, the patient, and the physical therapist is safe, reliable and highly effective.

\section{Disclosure}

No conflicts of interest were declared by the authors.

\section{Statement of Informed Consent}

All study participants provided informed written consent prior to study enrollment.

\section{Statement of Human Rights}

All procedures followed were in accordance with the Helsinki Declaration of 1975, as revised in 2008. Informed consent was obtained from all patients for being included in the study.

\section{References}

1. Codman EA (1934) The Shoulder. Thomas Todd, Boston, USA.

2. Harryman DT II (1993) Shoulders: Frozen and stiff. Instr Course Lect 42: 247-257.

3. Murnaghan JP (1990) Frozen shoulder, in Rockwood CA Jr, Matsen FA III (eds): The Shoulder. Philadelphia: WB Saunders pp 837-862.

4. Neviaser RJ, Neviaser TJ (1987) The frozen shoulder: Diagnosis and management. Clin Orthop 223: 59-64.

5. Zuckerman JD, Cuomo F (1992) Frozen shoulder, in Matsen FA III, Fu FH, Hawkins RJ (eds): The Shoulder: A Balance of Mobility and Stability. Rosemont, Ill: American Academy of Orthopaedic Surgeons pp 253-267.

6. Janda DH, Hawkins RJ (1993) Shoulder manipulation in patients with adhesive capsulitis and diabetes mellitus: A clinical note. J Shoulder Elbow Surg 2: 36-38.

7. Neviaser JS (1945) Adhesive capsulitis of the shoulder: A study of pathological findings in periarthritis of the shoulder. J Bone Joint Surg 27: $211-222$.

8. Shaffer B, Tibone JE, Kerlan RK (1992) Frozen shoulder: A long-term follow-up. J Bone Joint Surg Am 74: 738-746.

9. Hawkins RJ, Angelo RL (1990) Glenohumeral osteoarthritis: A late complication of the Putti-Platt repair. J BoneJoint Surg Am 72: 11931197.

10. Lusardi DA, Wirth MA, Wurtz D (1993) Loss of external rotation following anterior capsulorrhaphy of the shoulder. J Bone Joint Surg Am 75: 1185-1192.

11. Kieras DM, Matsen FA III (1991) Open release in the management of refractory frozen shoulder. Orthop Trans 15: 801-802.

12. MacDonald PB, Hawkins RJ, Fowler PJ (1992) Release of the subscapularis for internal rotation contracture and pain after anterior repair for recurrent anterior dislocation of the shoulder. J Bone Joint Surg Am 74: 734-737.

13. Neer CS, Satterlee CC, Dalsey R (1992) The anatomy and potential effects of contracture of the coracohumeral ligament. Clin Orthop 280: 182-185.

14. Neer CS II (1990) Frozen shoulder, in Neer CS II (ed): Shoulder Reconstruction. WB Saunders, Philadelphia, USA, pp 422-427. 
15. Ozaki J, Nakagawa Y, Sakurai G (1989) Recalcitrant chronic adhesive capsulitis of the shoulder: Role of contracture of the coracohumeral ligament and rotator interval in pathogenesis and treatment. J Bone Joint Surg Am 71: 1511-1515.

16. Duplay $S$ (1872) De la pèri-arthrite sacapuo-humèrale te ces raideurs de l'epaule qui en sont le consèquence. Arch Gen Med 20: 513.

17. Simon WH (1975) Sofá tissue disorders of shoulder. Rozen shoulder, calcific tendonitis, and bicipital tendonitis. Orhop Clin North Am 6: 521.

18. Kwang-Il Kwa, Eun-Kyung Kim (2016) The clinical effect of hydraulic distension plus manual therapy on patients with frozen shoulder. J Phys Ther Sci 28(8): 2393-2396.
19. James Wilson, Sarah Russell Mike J Walton (2015) The Management of Frozen Shoulder. Current Physical Medicine and Rehabilitation Reports 3(2): 181-187.

20. De Palma A (1973) Surgery of the Shoulder, $2^{\text {nd }}$ edition. Philadelphia, Lippincott, USA.

21. Reeves B (1966) Arthrographic changes in frozen shoulder and posttraumatic stiff shoulder. Proc R Soc Med 59: 827.

22. Lloyd J, Lloyd H (1983) Adhesive capsulitis of the shoulder. Arthrographic diagnosis and treatment. South Med J 76: 879.

\section{Your next submission with Juniper Publishers will reach you the below assets}

- Quality Editorial service

- Swift Peer Review

- Reprints availability

- E-prints Service

- Manuscript Podcast for convenient understanding

- Global attainment for your research

- Manuscript accessibility in different formats

( Pdf, E-pub, Full Text, Audio)

- Unceasing customer service

Track the below URL for one-step submission https://juniperpublishers.com/online-submission.php 